computing the actual ventricular rates from the records.

Apart from these criticisms, the letterpress is good, and the electrocardiograms have been well reproduced.

\section{MODERN OPERATIVE SURGERY}

Vol. I

Edited by G. GRey TURNER, D.Ch., LL.D., M.S., F.R.C.S., F.A.C.S.(Hon.). Cassell \& Co., Ltd., London. 1943. Price 50s.

There are many methods of reviewing books. The volume in question can be read from cover to cover. It is very tempting, however, when a surgeon reviews a book on operative surgery for him to turn first of all to those chapters dealing with conditions with which he is most familiar and read these firs:. An eminent pathologist was once asked his cpinion on a volume of surgery. His reply was that the pathology was hopelessly bad and incorrect, but the surgery appeared to him to be good.

This is what the chapter on gastric surgery advocates lor perforation of a peptic ulcer. "A small suprapubic incision should be made. The diagnosis is confirmed from the nature of the exudate, and a tube is inserted down to the bottom of the pelvis to allow the fluid to drain away during the operation. An upper right paramedian incision is now made. The perforation is as a rule easily found on the anterior surface of the stomach or duodenum. .. The next question that will arise is whether a gastro-enterostomy should be performed. In large part this will depend upon the experience of the surgeon and the time he is likely to occupy in carrying out this step. The majority of these ulcers are chronic. . . . The performance of the anastomosis at the time not only increases the likelihood of a permanent cure, but lessens the probability of gastric distension during convalescence. ... . If the condition is relatively good the gastro-enterostomy should be performed immediately after suture of the perforation. ..."

The book is called "modern" operative surgery. This treatment detailed above is twenty-five years old and has been discarded by most surgeons. Are the statements made true? Does a gastro-enterostomy cure a gastric ulcer! No, the author admits as much on page 685. "There was a high percentage of recurrence usually given at about 40 per cent." Does it diminish distension? No. Is the supra-pubic incision necessary in perforations under twelve hours old? No. Professor Grey Turner on page roor says, "Perforation of the stomach and duodenum can usually be treated without drainage and cannot be classed with the appendix perforations." The reference to the literature is Deaver, rgrg. Has nothing worthwhile been published since?

The treatment of hypertrophic pyloric stenosis is equally out of date. The author advocates warmed ether vapour and gas and oxygen anaesthesia, makes no mention of the importance of breast feeding, isolation of the infants in hospital, and the general nursing details essential for success. His latest reference to the literature is Surgery Gyn. and Obstet., 1933. The recent English literature has been completely ignored. The discussion at the Royal Society of Medicine has been passed over. Here local anaesthesia was advocated and a series of roo babies operated on under ideal conditions with no death reported. The author's mortality for eighty children is 18.7 per cent.

There is a perfectly delightful chapter on intestinal suture which to some extent takes away one's sense of disappointment with the section on gastric surgery. One must, however, ask whether Professor Grey Turner has fulfilled his duties as editor to allow such statements above to be printed.

In the preface, Grey Turner says, "As editor may I say that on a few occasions when I have found myself in disagreement with the authors I have not cared to worry the reader with dictatorial footnotes." Is this attitude justifiable? Professor Grey Turner is a man of wide experience. If this book is taken by an inexperienced surgeon into, say, the wilds of India, he may turn to it as his guide. If, then, he is confronted by a patient with a perforated gastric ulcer and proceeds to suture the perforation, and then do a gastro-enterostomy because the patient looks well, the patient may quite likely lose his life as a result. Is it justifiable. to sacrifice the lives of the unknown patients to a sense of loyalty to a colleague?

Furthermore, a technical handbook on operative surgery should not contradict itself, but should advocate a policy which in the experience of the most competent authority is the safest to be adopted by the inexperienced.

Many operations which have been advocated by this book we have discarded. We have used Nikola's operation with good results for recurrent. dislocation of the humerus. This book states, "The inevitable injury to the articular cartilage in the operation constitutes a serious objection to its use."

We have had no success with the flap operation advocated for close webbing of the fingers. Lasting cure in our hands has followed separation of the fingers and immediate skin grafting on a stent mould.

We should like to know Professor Grey Turner's views on these and many other matters. May the next edition of this book contain more of his. personality.

\section{NON-PULMONARY TUBERCULOSIS}

By Michael C. Wilkinson. Hamish Hamilton, Ltd. I942. Ios. 6d.

In vain did the reviewer search for the clinical description of the many conditions discussed in this otherwise excellent book. This omission, which it is to be hoped was a deliberate one, does detract very much from the practical value of this book.

The therapeutic side of non-pulmonary tuberculosis is, however, discussed freely and extremely well. The paramount importance of the constitutional treatment of the patient is stressed again and again, and very rightly; in tuberculosis anywhere in the body this angle must always be stressed even before mechanical measures are taken.

The general format of the book is good, but the radiograms of the chest might have been rather better reproduced, and it is interesting to note that Fig. 4 has been reproduced the wrong way round! But for all those interested in the subject of treatment, and of the results obtained therefrom, in non-pulmonary tuberculosis, this book should prove very valuable and interesting. 